ADVANCES IN NEUROPSYCHIATRY

\title{
Protein aggregates and dementia: is there a common toxicity?
}

\section{S Lovestone, D M McLoughlin}

J Neurol Neurosurg Psychiatry 2002;72:152-161

This review considers some of the recent advances made in the understanding of the pathogenic proteins known to aggregate and be implicated in neurodegenerative dementing disorders. It concentrates on the two most obvious candidates for the role of toxic protein in Alzheimer's disease (AD) - $\beta$-amyloid peptide and tau-but also considers other proteins in this disorder and in less common but equally devastating diseases.

See end of article for authors' affiliations

\section{Correspondence to:} Professor S Lovestone, Section of Old Age Psychiatry, Institute of Psychiatry, De Crespigny Park, London SE5 8AF, UK s.lovestone@iop.kcl.ac.uk

Received

26 January 2001

In revised form 30 May

2001

Accepted 27 June 2001
A berrant intracellular or extracellular deposition of self aggregating misfolded proteins is a common finding in primary neurodegenerative disorders such as Alzheimer's disease and other diseases that cause dementia. Although composed of unrelated proteins, these aggregates of initially soluble proteins have many common features. They usually have a dense fibrillar morphology with a high proportion of $\beta$-pleated sheet secondary structure, are often ubiquitinated, and are typically resistant to proteolytic degradation. Mutations in the relevant proteins cause familial forms of disease, either by producing abnormally fibrillogenic proteins/ peptides and/or by altering the normal intracellular distribution of the protein and thus accelerating the kinetics of aggregation, thereby giving rise to early onset disease.

Formation of protein aggregates may be a critical, albeit lengthy, pathogenic step. If so, their presence should be directly implicated in neurotoxicity; furthermore, aggregate formation should correlate with disease onset and progression, and the regional cerebral location of aggregate deposits should correspond to both the pattern of neurodegeneration and the clinical syndrome. The alternative is that aggregates are not causative but just a consequence of a primary disease process or represent a defensive response to cell death in postmitotic neurons. The presence of mutations in the genes coding for the aggregated proteins in many instances (for example, synuclein, Huntingtin, tau) suggests that protein aggregation is pathogenetic-cause rather than consequence. However, the relation between site and extent of aggregation and disease phenotype is far from proved and for some familial conditions the relation between gene affected and protein aggregated is less direct (for example, presenilin-1).

None the less, these abnormal proteinaceous deposits are characteristic disease features, providing remarkable clues about molecular patho- genesis and suggest shared aetiological mechanisms and therapeutic approaches. In this review we consider some of the recent advances made in our understanding of the pathogenic proteins known to aggregate and be implicated in neurodegenerative dementing disorders, concentrating on the two most obvious candidates for the role of toxic protein in Alzheimer's disease - $\beta$-amyloid peptide and tau-but also considering other proteins in this disorder and in less common but equally devastating diseases.

\section{$\beta$-AMYLOID PEPTIDE: AN UNDISPUTED TOXIC PROTEIN}

Extracellular cerebral amyloid deposition in neuritic plaques is one of the hallmarks of Alzheimer's disease and amyloid deposition itself is one of the earliest pathological abnormalities, preceding paired helical filament tau formation and neurofibrillary tangles (NFTs). ${ }^{1}$ Neuritic plaques are relatively insoluble dense cores of 5-10 nm thick amyloid fibrils with a paler staining "halo" surrounded by dystrophic neurites, reactive astrocytes, and activated microglia. The main protein component of amyloid in Alzheimer's disease is the 39-42 amino acid $\beta$-amyloid peptide $(A \beta)$, which is a normal proteolytic breakdown product of the much larger membrane spanning amyloid precursor protein (APP; fig 1).

The fibrillogenicity of $A \beta$ is dictated by peptide length such that the less common $A \beta_{42}$ variant $(\sim 10 \%$ of total $\mathrm{A} \beta)$ is more fibrillogenic than the more commonly produced but shorter $A \beta_{40} . A \beta_{42}$ is the main species initially deposited in immature "diffuse" plaques in both Alzheimer's disease and Down's syndrome; it forms a "seed" for future mature neuritic plaque development, ${ }^{23}$ a process that takes at least 10-15 years and antedates symptoms by possibly even longer. Although little is known about its normal function, there is a consensus that aggregation of $A \beta$ into amyloid is required for neurotoxicity. The precise nature of $\mathrm{A} \beta$ mediated neurotoxicity remains to be elucidated but proposed mechanisms include oxidative stress, free radical generation, altered calcium

Abbreviations: NFTs, neurofibrillary tangles; $A \beta$, $\beta$-amyloid; APP, amyloid precursor protein; PS1, presenilin-1; PS2, presenilin-2; APP ${ }_{s \alpha}$, APP ectodomain apoE, apolipoprotein $\mathrm{E}$; apoE $\%$, Dabl, disabled-1 intracellular adaptor protein; PTB, phosphotyrosine binding; GSK-3, glycogen synthase kinase-3; PrPC, normal cellular prion protein

A glossary to terms is located at the end of the review 
Table 1 Pathogenic proteins and their aggregates in dementia

\begin{tabular}{|c|c|c|c|}
\hline Protein/peptide & Disorder & Aggregate & Neuronal location \\
\hline $\mathrm{APP} / \mathrm{A} \beta$ & Alzheimer's disease & Amyloid & Extracellular \\
\hline Tau & $\begin{array}{l}\text { Alzheimer's disease, FTDP-17, } \\
\text { Pick's disease, CBD, PSP }\end{array}$ & $\begin{array}{l}\text { Paired helical and } \\
\text { straight filaments }\end{array}$ & Cytoplasmic \\
\hline \multirow[t]{2}{*}{$\alpha$-Synuclein } & Parkinson's disease, DLB & Lewy body & Cytoplasmic \\
\hline & Multisystem atrophy & Inclusion body & Glial cells \\
\hline Huntingtin & Huntington's disease & Inclusion body & Cytoplasmic and intranuclear \\
\hline Prion protein & Prion disorders & Amyloid & Extracellular \\
\hline
\end{tabular}

APP, amyloid precursor protein; $A \beta$, $\beta$-amyloid peptide; FTDP-17, frontotemporal dementia with parkinsonism linked to chromosome 17; CBD, corticobasal degeneration; PSP, progressive supranuclear palsy; DLB, Dementia with Lewy bodies.

homeostasis, induction of apoptosis, chronic inflammation, and neuronal structural damage. ${ }^{4}$ Although undisputedly toxic to cells in culture when aggregated and almost certainly toxic when injected or overexpressed in animals, some questions remain. In particular, the relative roles of intracellular versus extracellular amyloid and the role of the plaque itself remain to be fully characterised. None the less, most researchers would now accept that the formation and aggregation of amyloid is the most likely starting point of Alzheimer's disease pathogenesis in vivo.

\section{THE AMYLOID CASCADE HYPOTHESIS OF ALZHEIMER'S DISEASE}

Increased production of the more fibrillogenic $A \beta_{42}$ has been associated with all of the autosomal dominantly inherited forms of Alzheimer's disease caused by mutations in the genes encoding APP, presenilin-1 (PS1) and presenilin-2 (PS2). ${ }^{5}$ In addition, Down's syndrome due to trisomy 21 (but only when including the APP gene on proximal chromosome 2lq, thus causing a "gene dosage" effect) invariably causes Alzheimer's disease. These findings, coupled with the importance of APP as the precursor of $A \beta$, have endorsed the "amyloid cascade hypothesis" of Alzheimer's disease, which posits a central aetiological role for $A \beta$, leading to neurofibrillary pathology and neuronal death (fig 2 ).

Limitations of the hypothesis include the finding that neuritic plaque counts do not correlate with disease severity as well as do other pathologies such as synaptic loss or numbers of NFTs. However, analysis of total amyloid burden and total $\mathrm{A} \beta$ concentrations correlates better with clinical progression

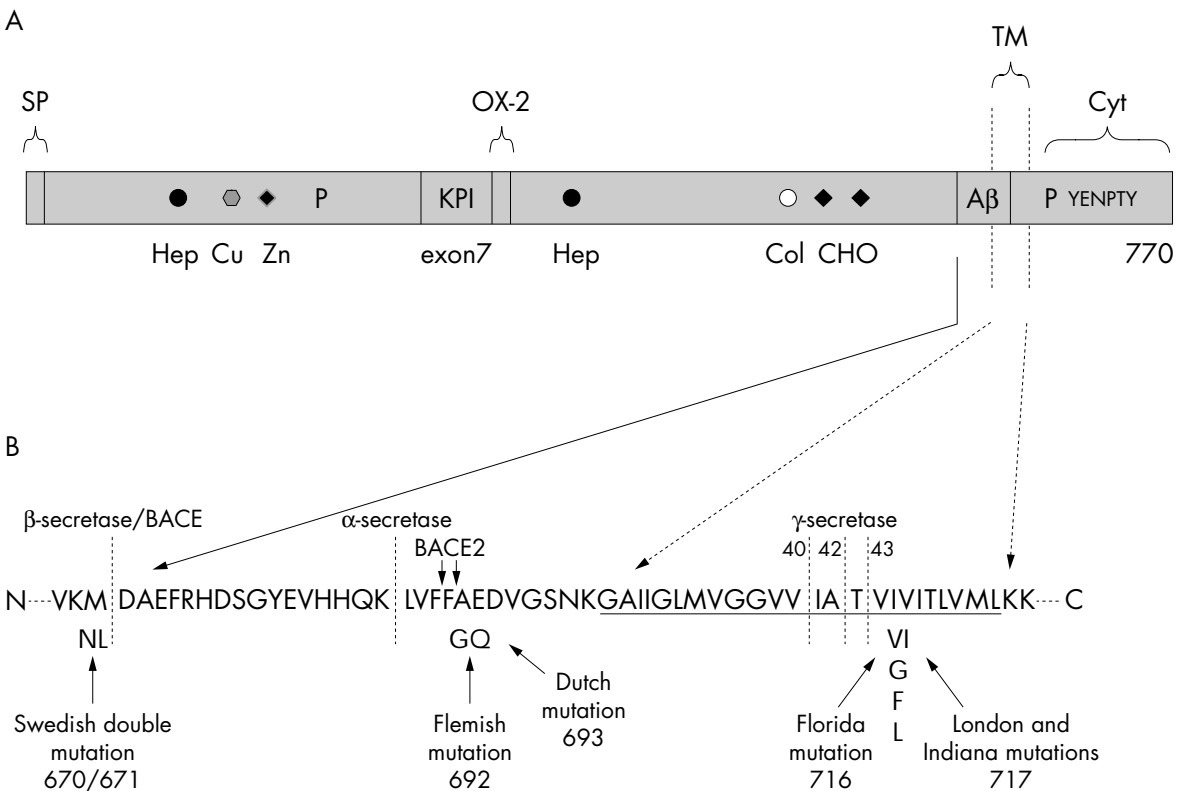

Figure 1 Structure of the amyloid precursor protein. (A) Schematic diagram of the longest APP splice isoform (APP location of different binding and functional domains. Exons 7 and 8, encoding respectively the Kunitz protease inhibitor domain (KPI) and the MRC-OX2 antigen (OX-2) sequence, are alternatively spliced to generate different APP isoforms. The signal peptide (SP) is cleaved after cotranslational translocation to the membrane of the endoplasmic reticulum. As APP molecules are processed through the endoplasmic reticulum and Golgi apparatus they undergo post-translational modifications at specific sites, including glycosylation (CHO) and phosphorylation (P). APP has several specialised binding domains to interact with components of the extracellular matrix, including heparin (Hep) and collagen (Col), as well as to the metals copper (Cu) and zinc (Zn). The $\beta$-amyloid peptide (A $\beta)$ sequence partially resides in the transmembrane (TM) region. The YENPTY re-internalisation motif in the cytoplasmic domain (Cyt) also contains the NPXY motif for binding PTB domains. Re-internalisation of plasma membrane bound APP directs it towards an amyloidogenic pathway. (B) Expansion of the amino acid sequence of A $\beta$ (shown in bold) and the transmembrane region of APP (underlined). Secretase cleavage sites are indicated by dashed lines and the location of pathogenic mutations in APP are shown. Note that the sites of the missense mutations are either flanking or within the A $\beta$ sequence and also near to sites of secretase cleavage. Secreted forms of APP (APP) are released into the extracellular space after cleavage of cell membrane bound APP within the $A \beta$ sequence at amino acids $16 / 17$ by $\alpha$-secretase. The remaining membrane bound $C$ terminal 83 amino acid fragment (C83) is further cleaved by $\gamma$-secretase to generate a peptide fragment known as P3. This constitutive secretory pathway precludes formation of intact $A \beta$. Alternative cleavage of APP by $\beta$-secretase generates a slightly truncated secreted APP (APP s ) and a membrane bound 99 residue $C$ terminal fragment (C99). Cleavage of C99 by $\gamma$-secretase allows the release of intact $A \beta$. 


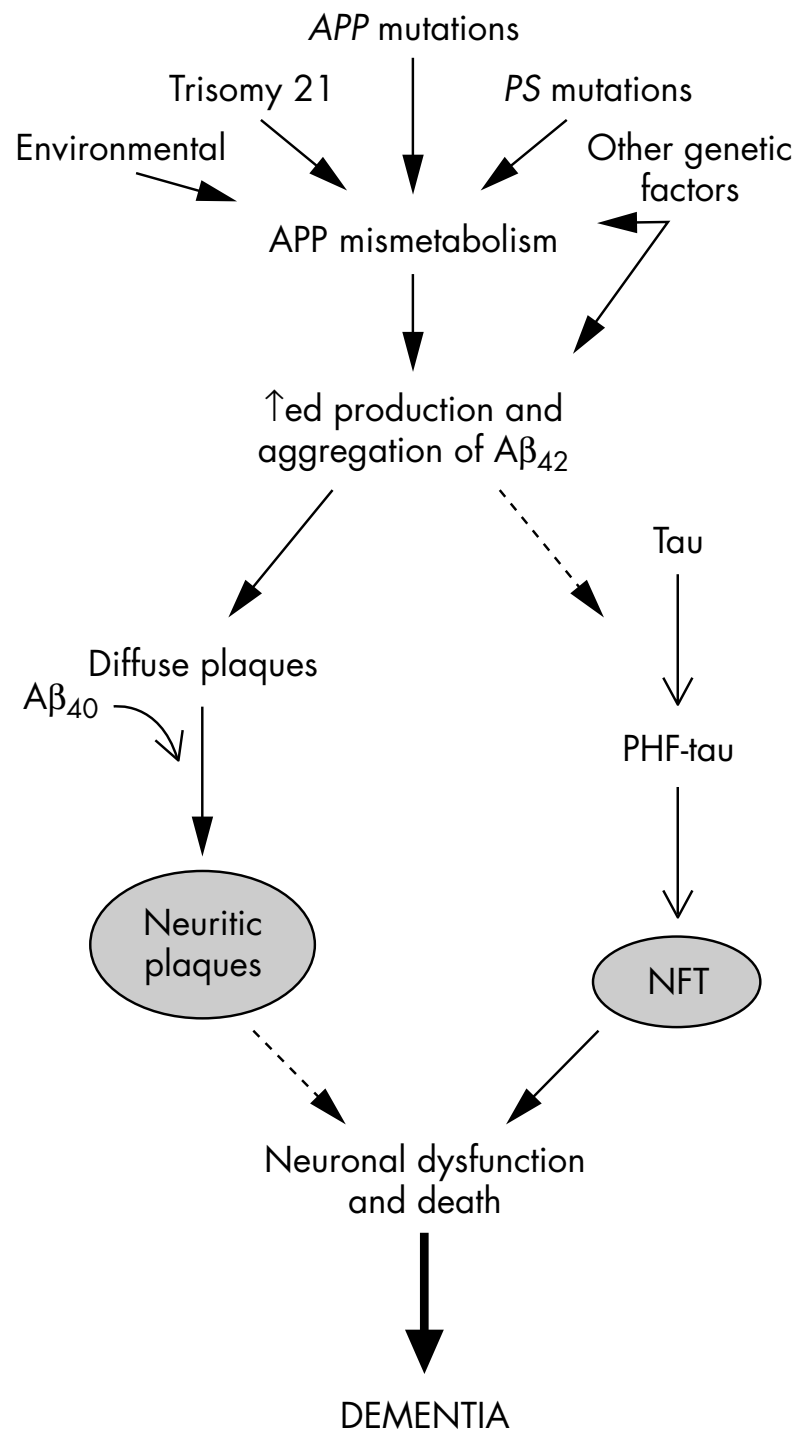

Figure 2 The amyloid cascade hypothesis. A model of the sequence of pathogenic events in Alzheimer's disease. The broken lines indicate possible, but not definitively proved, pathways. The pathway on the left (closed arrowheads) charts the evolution of the amyloid pathology and the pathway on the right (open arrowheads) is for the tau/cytoskeletal pathology. PHF, paired helical filament; NFT, neurofibrillary tangle.

than do analyses of plaques alone. ${ }^{6}$ Another difficulty is that, unlike the stereotypical development and hierarchical distribution of NFTs, amyloid plaque distribution is variable in Alzheimer's disease brain and plaques are not necessarily detectable in high quantities in cerebral regions where cell death and loss occurs. ${ }^{7}$ Finally, no direct link has yet been established between APP and/or A $\beta$ and the NFT pathology. Interestingly, mutations in the tau gene indisputably cause NFTs and neurodegeneration (see below) but are not associated with amyloid pathology, whereas mutations in APP and the presenilins cause both amyloid and tau pathology. Thus tau is genetically downstream of APP and the presenilins, but this does not rule out an important aetiological role for NFTs in the clinical picture. One possibility is that abnormalities in APP metabolism result in dysregulation of intracellular signalling pathways leading to aberrant phosphorylation of tau, NFT formation and neurodegeneration. However, to date, most transgenic mice overexpressing mutant or wild type APP or presenilins have not developed convincing

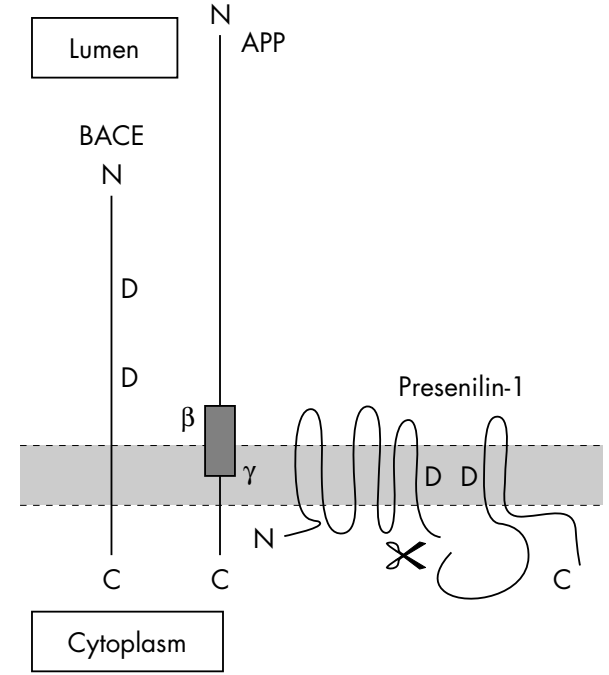

Figure $3 \beta$-Secretase- and $\gamma$-secretase cleavage of APP. Schematic diagram depicting endoplasmic reticulum/Golgi membrane bound APP, BACE, and PS 1. D, conserved aspartic acid residues that are candidate active sites for proteolytic activity (see text). Note that these sites are located in the luminal ectodomain of BACE, whereas in PS1 they reside within transmembrane regions 6 and 7 , respectively, of the $\mathrm{N}$ and $\mathrm{C}$ terminal fragments of PS1. The endoproteolytic cleavage site of PS1 is indicated.

NFT pathology, even in the presence of substantial amyloid deposits reminiscent of Alzheimer's disease. ${ }^{8}$

\section{APP, A $\beta$, AND THE FORMATION OF PLAQUES}

The proteolytic processing and intracellular trafficking of APP is complex and occurs through several routes (fig l). The normal function of APP is not yet clear but aberrant processing of APP causing either increased production, decreased removal, or the production of abnormally amyloidogenic $A \beta$ is possibly the primary pathogenic event in Alzheimer's disease. ${ }^{9}$ Ubiquitously expressed and highly evolutionarily conserved, APP is a membrane spanning protein comprising a large extracellular/ intraluminal amino(N)-terminal ectodomain, a single membrane spanning domain, and a short intracellular/cytoplasmic carboxyl(C) terminal domain (fig l).

There are, however, other pathways for APP processing that provide routes for the generation of intact $A \beta$. Two proteolytic enzyme activities ( $\beta$-secretase and $\gamma$-secretase) have been defined that allow A $\beta$ to be excised from within APP (fig l). $\beta$-Secretase cleaves APP at the N terminus of $A \beta$, generating a C99 fragment, and $\gamma$-secretase cleaves APP after the C terminus of $\mathrm{A} \beta$ - that is, actually within the hydrophobic transmembrane region. In the past 2 years extraordinary progress has been made in the identification and characterisation of these two secretases that hopefully should eventually lead to novel rational therapeutic targets for Alzheimer's disease.

The same candidate for $\beta$-secretase has been identified by several independent groups using different experimental approaches and has been named "BACE" ( $\beta$-site APP cleaving enzyme; chromosomal location is 1lq23.3) or "Asp2" or Memapsin2 as it is a membrane bound aspartyl protease. ${ }^{10-14}$ BACE is brain enriched and expression levels are much higher in neurons than in glia. It is a transmembrane protein with a short cytoplasmic tail and has been localised predominantly to the lumen of the Golgi apparatus and also to endosomes. There are two conserved Asp(Thr/Ser)Gly(Thr/Ser) motifs in its luminal ectodomain. These two motifs form the active site and, because of their orientation, have access to the $\beta$-cleavage site in the ectodomain of APP (fig 3). In support of BACE 
being $\beta$-secretase are that overexpression results in increased cleavage of APP at known $\beta$-secretase sites. ${ }^{10}{ }^{11}$ and inhibition of BACE activity results in decreased $\beta$-cleaved products. ${ }^{10} 12$

A homologue, BACE2/Aspl, has also been identified, indicating that there is a family of these novel membrane spanning aspartyl proteases. The gene for BACE2 is in the critical Down's syndrome region of chromosome $21 .{ }^{15}$ Neuronal expression of BACE2 is very low, ${ }^{16}$ however, and BACE2 predominantly cleaves within the $A \beta$ sequence rather than at the $\mathrm{N}$ terminus. ${ }^{17}$ These findings tend to mitigate against a role for BACE2 in Alzheimer's disease pathogenesis in Down's syndrome but might implicate BACE2 in the Alzheimer's disease pathology associated with the "Flemish" APP mutation, the site of which is beside the newly identified BACE2 A $\beta$ cleavage site (fig 1).

\section{THE PRESENILINS AND $\gamma$-SECRETASE}

The presenilin proteins (PS1 and a homologue PS2) are 463 and 448 amino acid proteins with predicted eight transmembrane domain serpentine structures (fig 3) and are localised mainly to the membranes of the endoplasmic reticulum and cis Golgi apparatus. ${ }^{18}$ Constitutive endoproteolysis within a large cytoplasmic loop domain gives rise to $\mathrm{N}$ and $\mathrm{C}$ terminal fragments that form stable heterodimeric complexes that seem to be the principal functional form. The PS proteins have been reported to have a wide range of functions, including control of Notch mediated developmental morphogenesis, subcellular transport, and apoptosis, but it is becoming increasingly apparent that the PS proteins regulate $\gamma$-secretase activity.

PS1 knockout mice are embryonic lethal or die shortly after birth and display severe disruption of somitogenesis and axial skeleton development plus forebrain neurodevelopmental abnormalities, ${ }^{192}$ a phenotype similar to Notch knockout mice. $^{21}$ Remarkably, cultured neurons from PSI knockout embryos demonstrate normal $\alpha$-secretase and $\beta$-secretase activities but substantially diminished $\gamma$-secretase activity, resulting in a five-fold decrease in $\mathrm{A} \beta$ production (and also the P3 peptide) along with an accumulation of $\alpha$-secretase and $\beta$-secretase generated C terminal APP stubs-that is, C99 and C83. ${ }^{22}{ }^{23}$ Knocking out both PS1 and PS2 eradicates $\gamma$-secretase cleavage of $\mathrm{APP}^{24}$ In transmembrane regions 6 and 7 of PS 1 there are two aspartic acid residues (Asp257 and Asp385, respectively) that are conserved between all members of the PS family and that are candidate sites for intramembranous protease activity. Mutating either of these aspartic acid residues to alanine reduces $\gamma$-secretase cleavage of APP. $^{25}$ Asp385, in particular, is required for cleavage of APP by $\gamma$-secretase, whereas both sites seem to participate in Notch endoproteolysis. ${ }^{26}$ That some $\gamma$-secretase activity resides in PS 1 has been supported by studies using known transition state specific inhibitors of $\gamma$-secretase activity to bind, label, and identify PS 1 and also by detecting $\gamma$-secretase activity in PS 1 associated complexes. ${ }^{27-29}$

Taken together, these findings have led to the hypothesis that PS I might directly or indirectly regulate $\gamma$-secretase, perhaps as a diaspartyl cofactor or by post-translational modification of $\gamma$-secretase and/or APP, or indeed might actually be $\gamma$-secretase itself. However, the therapeutic viability of inhibiting $\gamma$-secretase could be limited as this may deleteriously affect Notch signalling pathways that are involved in haematopoeisis and myogenesis as well as neurodevelopment.

\section{APOLIPOPROTEIN E, APP, AND LATE ONSET ALZHEIMER'S DISEASE}

The $\epsilon 4$ allele of the gene encoding apolipoprotein $\mathrm{E}$ (ApoE) is the most robust susceptibility gene so far to be identified for late onset Alzheimer's disease. Possession of one $\epsilon 4$ allele lowers the age of onset by 5 years and two $\epsilon 4$ alleles by 10 years. A large population survival study has shown that the risk attributable to the apoE $\epsilon 4$ genotype is disease modifying-by lowering the age of onset-rather than causative. ${ }^{30}$

How ApoE modifies Alzheimer's disease pathogenesis is not yet known. As with the genetic defects in APP, PS1 and PS2, the apoE $\epsilon 4$ effect seems to be mediated through $A \beta$ either by enhanced aggregation or reduced clearance. For example, crossing apoE knockout mice $\left(\mathrm{apoE}^{-/}\right)$with mutant APPV717F transgenic mice results in mice at 6 months with only sparse diffuse $A \beta$ deposits compared with more widespread amyloid deposition in APPV717F:apoE ${ }^{+/+}$mice. ${ }^{31}$ Moreover, there is an increased $A \beta$ load in patients with Alzheimer's disease with an apoE $\epsilon 4$ genotype. ${ }^{32}$ ApoE4 related pathogenic mechanisms could be related to isoform specific activity-for example, ApoE4 has been shown in vitro to have a greater avidity for binding $A \beta$ compared with the other isoforms ${ }^{33}$ and a lower efficacy for interacting with tau and protecting it from hyperphosphorylation and possible NFT formation. ${ }^{3435}$

Cerebral ApoE receptors are abundantly expressed on neurons but ApoE is actually produced by astrocytes. ApoE mediates phospholipid and cholesterol mobilisation and distribution and is active in membrane remodelling and maintenance of synaptic plasticity. ${ }^{36}$ It could be that apoE4 performs these reparative functions less effectively than the E3 or E2 isoforms, thereby bringing forward the onset of dementia in persons developing Alzheimer's disease.

\section{APOE, REELIN, AND ADAPTOR PROTEINS IN ALZHEIMER'S DISEASE}

ApoE also functions in the reelin signalling pathway, which is essential for the proper migration of developing neurons. At the neuronal surface, reelin binds to both the very low density lipoprotein (VLDL) receptor and the ApoE receptor-2 (ApoER2), two members of the family of low density lipoprotein (LDL) receptors to which ApoE also binds. This induces phosphorylation of the disabled-1 (Dabl) intracellular adaptor protein (a protein that provides a molecular "scaffolding" for the formation of multiprotein complexes), which is required for propagation of the intracellular reelin signal; defects in this pathway can apparently cause hyperphosphorylation of tau similar to that found in Alzheimer's disease. ${ }^{37}$ Dabl also binds to a sequence within the cytoplasmic domain of APP containing the NPXY re-internalisation motif (fig l), which regulates endocytosis of cell surface APP. ${ }^{38}$ The NPXY motif also acts as a binding site for proteins that contain a PTB (phosphotyrosine binding) domain, a well characterised type of modular protein-protein interaction domain. In addition to binding to the Dabl PTB domain, the cytoplasmic domain of APP also binds to members of two other PTB domain containing adaptor protein families, the Fe65s and the X11s. ${ }^{39}$

Both Fe65 and Fe65Ll have been reported to enhance trafficking of APP through the secretory pathway and promote secretion of $\mathrm{APP}_{\mathrm{s} \alpha}$ and, in the case of Fe65, to also increase secretion of $A \beta$ in cultured cells. ${ }^{40}{ }^{41}$ The Xl ls seem to have the opposite effect on APP processing in that the neuron specific $\mathrm{X} 11$ proteins $\mathrm{X} 11 \alpha$ and X11 $\beta$ stabilise intracellular APP and decrease secretion of $A \beta$ from cultured cells. ${ }^{42-45}$ Of note, XIIX and XII $\beta$ have been reported to bind to the C-terminus of PS 1 and to mediate PSI binding to the cytoplasmic domain of APP. $^{46}$

It has been proposed that Fe65 can simultaneously bind, via its two PTB domains, to NPXY motifs within the cytoplasmic domains of both APP (fig l) and the low density lipoprotein (LDL) receptor related protein (LRP), another member of the LDL receptor family, while Dabl binds to a second NPXY motif in the cytoplasmic domain of LRP. ${ }^{38}$ Via its extracellular domain, LRP has been reported to bind KPI domain containing APP isoforms, promote reinternalisation of APP and thereby increase secretion of $A \beta{ }^{47}$ Thus, in summary, a theoretical framework is beginning to emerge, centering 
around a complex series of interactions between the cytoplasmic domain of APP, various cytoplasmic adaptor proteins and members of the LDL receptor family, that functionally couples ApoE to intracellular signalling, phosphorylation of tau, and processing of APP

\section{OTHER GENETIC FACTORS IN ALZHEIMER'S DISEASE}

ApoE $\epsilon 4$ clearly does not account for the entire familial component in late onset Alzheimer's disease. A genome scan has identified several other candidate linkage sites including sites on chromosomes 12 and $10{ }^{48}$ An intronic polymorphism in the gene coding for $\alpha 2$-macroglobulin ( $\alpha 2 \mathrm{M}$; located on chromosome 12), which binds to LRP and also to $A \beta$, has been reported by one group to be associated with increased risk for late onset Alzheimer's disease. ${ }^{49}$ Although $\alpha 2 \mathrm{M}$ is an attractive candidate, this finding has not been substantiated by most other independent groups and the chromosome 12 locus remains to be identified. Most recently, linkage has been confirmed to a region of chromosome 10q. ${ }^{50}$ One possible candidate here is the insulin degrading enzyme (IDE), ${ }^{52}$ which has been identified as having a role in the degradation and clearance of $A \beta$ secreted by neurons and microglia. ${ }^{53}$ Undoubtedly, the search for new genetic risk factors for Alzheimer's disease will continue and it would be most unusual if these did not turn out to have a role in modulating APP processing and generation of $\mathrm{A} \beta$.

\section{TAU: THE PROTEIN OF TANGLES}

Tau was first implicated as a protein involved in the pathogenesis of Alzheimer's disease when it was discovered to be a major component of the neurofibrillary tangle described by Alzheimer himself. ${ }^{5455}$ In tangles highly phosphorylated tau aggregates, in the form of paired helical filaments, gradually replace the normal neuronal cytoskeleton. However, some questions remain-is tau aggregation a primary pathogenic event or a secondary epiphenomenon? Does tau phosphorylation occur before or after aggregation? And is it the aggregation that is pathogenic or the loss of the normal function of tau?

Tau is a normal component of the neuronal cytoskeleton, a microtubule associated protein, expressed predominantly in axons where it functions to stabilise microtubules which are essential for fast axonal transport. This function of tau is regulated at the genomic and the proteomic level. Genetic regulation of the function of tau is by differential splicingthere are six isoforms of tau in CNS, differing by possession of $\mathrm{N}$-terminal inserts of unknown function and by possession of three or four imperfect repeats that bind to microtubules. Tau with four microtubule binding domains binds microtubules better and this is reflected in the predominance of three repeat tau in the relatively unstable and dynamic developing brain. Proteomic regulation of tau function is by phosphorylationthe more phosphorylated tau fails to bind and stabilise microtubules as well as unphosphorylated tau. In parallel with the genetic regulation of tau function, developmental brain tau is more highly phosphorylated than mature adult brain tau. (For more detailed reviews of the biology of tau in health and disease see Spillantini and Goedert, ${ }^{56} \mathrm{Lee}^{57}$ and Lovestone and Reynolds. ${ }^{58}$ )

Although it was known for more than 10 years that tau was aggregated in Alzheimer's disease, it took a genetic disease to finally demonstrate that tau pathology could be primary in dementia. ${ }^{59}$ Mutations in the tau gene were found first in frontotemporal degeneration with parkinsonism linked to chromosome 17, a disorder with predominant tau positive aggregations in glia as well as in neurons. ${ }^{60}$ Other tau inclusion disorders (now subsumed under the term the tauopathies) include frontal lobe dementia, corticobasal degeneration, and progressive supranuclear palsy ${ }^{61}$ Mutations in tau have now been found in families with diverse frontal lobe dementing conditions including some which very closely resemble Pick's disease $^{6263}$ and polymorphic variation in tau has been associated with progressive supranuclear palsy. ${ }^{64}$

The mutations in the autosomal dominant tauopathies are of two types-intronic mutations that disrupt the splicing of $\operatorname{tau}^{65}$ and missense mutations that alter the function of tau. ${ }^{66-68}$ Both the splicing of tau, resulting in the relative proportion of three and four repeat isoforms, and the function of tau (through phosphorylation) are normally tightly regulated. It is likely that it is loss of this normal regulation that somehow results in tau aggregation, although it should be noted that in vitro the mutations also increase tau aggregation itself. ${ }^{69} 70$ Transgenic mice carrying tau mutations exhibit behavioural and neuropathological correlates of the disease process and are the first in vivo models of tau aggregation. ${ }^{71}$ Thus the first question was answered-tau aggregates are indeed a sign of primary pathology and not a secondary epiphenomenon. Tau aggregation without amyloid pathology is sufficient to cause a dementia in mice and in humans and hence the first question is answered-tau can clearly be a pathogenic protein.

Ironically this genetic demonstration of the importance of tau pathology also demonstrated the primacy of amyloid in Alzheimer's disease. As mutations in tau give rise to tangles but mutations in APP give rise to plaques and tangles it follows that amyloid must, biochemically, precede tau pathology in Alzheimer's disease. This confirms the observational studies on Down's syndrome brain where it was shown that amyloid deposition preceded tangle aggregation. ${ }^{72}$ However, somewhat against these findings are those of Braak and Braak who demonstrated in normal brain a gradual accumulation of highly phosphorylated tau, normally taken as a sign of pathology, that precedes amyloid deposition and dementia, by decades. ${ }^{73}$ In fact, tau phosphorylation is in itself not pathological but the extent of tau phosphorylation can be. In foetal brain tau is very highly phosphorylated, in normal brain tau is moderately phosphorylated, in postmortem normal brain tau becomes rapidly dephosphorylated but in Alzheimer's disease brain tau phosphorylation is maximal and stable. All the evidence points to one enzyme, glycogen synthase kinase-3 (GSK-3), being the predominant tau kinase in brain, although other kinases also phosphorylate tau (reviewed in Lovestone and Reynolds ${ }^{58}$ ).

Phosphorylation by GSK-3 renders tau less capable of binding microtubules and microtubules less stable and more liable to depolymerise. ${ }^{74}$ This raises the second unanswered question in relation to tau aggregation. It is possible that tau phosphorylation, after all a normal process probably being regulated on a moment to moment basis as the cytoskeleton responds to extracellular signals, does not precede tau aggregation but simply occurs as tau is accumulated into stable, insoluble aggregates, perhaps preceded by proteolytic events. ${ }^{75} 76$ In truth there is little to argue for phosphorylation being chicken or egg at present. Our own laboratory is interested in the finding that both tau mutations and tau phosphorylation have the effect of disassembling tau from microtubules and result in tau accumulation in the cytoplasm and, by the evidence that under certain conditions tau will readily self aggregate in vitro. ${ }^{77}$ It would seem plausible at least that any event, be it mutation, polymorphism, or phosphorylation, that resulted in tau accumulation in the cytoplasm would result in increased self aggregation and hence tangles. However, plausibility can be deceptive. It is transgenic animals that will demonstrate whether tau phosphorylation precedes or follows aggregation.

The third question is whether the aggregation of tau results in disease as a direct result of aggregation or whether there is loss of function of tau that might contribute to the disease phenotype. Tau as noted above stabilises the microtubule cytoskeleton and microtubules are essential for axonal transport. As axonal transport is necessary to replenish synaptic 
proteins then a failure of transport would result in loss of neuronal function. In disease aggregation of tau is mirrored by loss of microtubules. Is this a sign of the loss of the normal function of tau resulting in the loss of normal microtubules? The same thing is seen in cell models of Alzheimer-like tau phosphorylation ${ }^{74}$ but it might equally be that the gross accumulation of tau aggregates is in itself toxic to the cell. The finding that it is loss of microtubules (and not for instance loss of the actin cytoskeleton) that occurs in Alzheimer's disease may be a coincidence-a toxic gain of function-and not a sign of loss of function.

Tau aggregation is unequivocally associated with Alzheimer's disease and other neurodegenerative diseases and to this extent tau is a toxic protein in dementia. Tau, like the other proteins associated with dementia has a tendency to self aggregate. However, whether it is the tau aggregation that results in disease (toxic gain of function) or whether clinical phenotypes also result from a loss of the normal function of tau remains to be seen.

\section{SYNUCLEIN AND THE LEWY BODY}

In addition to amyloid fibrils the plaque of Alzheimer's disease contains many other proteins-the so called non-amyloid component (NAC). One of these proteins was found to be synuclein, ${ }^{78}$ a presynaptic membrane associated protein known to be important in learning in songbirds. ${ }^{79}$ However, synuclein came to prominence as a toxic protein in dementia after the demonstration that the fibrillar inclusion bodies in dementia with Lewy bodies and of Parkinson's disease were composed largely of this protein. ${ }^{80-82}$ Genetics again demonstrated that this was core to the pathology and not an epiphenomenon when mutations were found in a family with autosomal dominant Parkinson's disease. ${ }^{83}$ Synuclein aggregation also occurs in multisystem atrophy within glial inclusion bodies. ${ }^{84}$ A new classification of the neurodegenerative diseases has emerged from these findings-the tauopathies to include frontotemporal degeneration with parkinsonism and progressive supranuclear palsy by contrast with the synucleinopathies to include multiple system atrophy, Parkinson's disease, and dementia with Lewy bodies. Alzheimer's disease is simultaneously an amyloidopathy ( similar to familial British or Danish dementia) and a tauopathy. Mouse and fly models of synuclein overexpression generate a phenotype resembling Parkinson's disease with dopaminergic loss and Lewy body-like inclusions. ${ }^{85} 86$

Like other of the proteins we have been considering (tau for example) synuclein is a normal protein that is developmentally regulated-becoming associated with the synapse on maturity ${ }^{878}$ Mice lacking synuclein display a subtle phenotype indicative of dopaminergic neuronal abnormality ${ }^{89}$ Again similar to tau, mutations in the synuclein gene result in a protein that self aggregates more readily than wild-type synuclein $^{90-92}$ and, having aggregated, mutant synuclein can act as a nidus for aggregation of both wild type and mutant synuclein..$^{93}$ However, the mutation also seems to reduce turnover of synuclein by the proteosome. ${ }^{94}$ Thus there is another symmetry with tau as mutations in both genes result in proteins that, at least in vitro and in cultured cells, show increased self aggregation and increased cytoplasmic accumulation.

\section{PRION PROTEIN AND TRANSMISSABLE SPONGIFORM ENCEPHALOPATHIES}

The prion disorders are rare transmissable diseases of the CNS with long incubation periods that affect humans and other animals. Classically, there is variable vacuolation of the neuropil giving rise to a "sponge-like" appearance in the brain, neuronal loss, gliosis, and extracellular amyloid plaques. The main constituent of the amyloid is $\operatorname{PrP}^{\mathrm{sc}}$, which is named after the sheep prion disorder scrapie and is a modified partially protease resistant and more aggregable form of the normal cellular prion protein $\left(\operatorname{PrP}^{\mathrm{C}}\right) \cdot{ }^{95}$ Prion disorders can be inherited, infectious, or sporadic in origin. In addition, inherited forms can also be infectious-that is, they can be transmitted from one animal to another after either deliberate or accidental/iatrogenic inoculation with affected tissue. The appearance of variant Creutzfeld-Jakob disease, thought to be due to ingestion of material from cattle with bovine spongiform encephalopathy, has demonstrated that disease associated $\mathrm{PrP}^{\mathrm{sc}}$ can in certain instances cross a species barrier. ${ }^{96}$

Human $\operatorname{PrP}^{C}$ is a 253 amino acid membrane associated glycoprotein expressed by neurons and to a lesser extent by astrocytes. An N-terminal 22 amino acid signal peptide is cleaved off after translation and the C-terminal 23 residues are also subsequently removed, following which a glycosyl phosphatidyl inositol (GPI) molecule is attached to serine230. This GPI molecule links mature $\operatorname{PrP}^{C}$ to the outer cell surface where $\operatorname{PrP}^{C}$ can be endocytosed and recycled within the cell. The C-terminal two thirds of the protein has a three helix bundle structure, whereas the N-terminal third is less obviously structured but does include four copper binding octapeptide (PHGGGWGQ) repeat motifs. Binding of transitional copper ions possibly protects against copper toxicity and also has a role in $\operatorname{PrP}^{\mathrm{C}}$ antioxidant function. ${ }^{97} \operatorname{PrP}^{\mathrm{C}}$ may also have a role in synaptic function as it is axonally transported to synaptic boutons and some mice in which the prion gene (Prnp) has been knocked out $\left(\operatorname{Prnp}^{0 / 0}\right)$ have abnormalities in long term potentiation. ${ }^{98}$

The primary sequences of $\operatorname{PrP}^{\mathrm{C}}$ and $\operatorname{PrP}^{\mathrm{sc}}$ are identical. So how can $\operatorname{PrP}^{\mathrm{sc}}$ be pathogenic? It is now generally believed that the differences between $\operatorname{PrP}^{\mathrm{sc}}$ and $\operatorname{PrP}^{\mathrm{C}}$ reside at the level of their tertiary and quaternary structures, in particular an increased $\beta$-sheet content in $\operatorname{PrP}^{\mathrm{Sc}}$, and that these differences confer pathogenicity on $\mathrm{PrP}^{\mathrm{sc}} .{ }^{95}$ Indeed, these conformational differences endow $\operatorname{PrP}^{\mathrm{Sc}}$ with the ability to convert normal host encoded $\operatorname{PrP}^{\mathrm{C}}$ to $\operatorname{PrP}^{\mathrm{Sc}}$ and thereby facilitate and extend the disease process in an infectious manner. $\operatorname{PrP}^{\mathrm{sc}}$ thus truly seems, even in the absence of any nucleic acid, to be a "proteinaceous infectious particle". What mediates this conversion process is not known but it seems to occur as a late post-translational event, either at the cell surface or after endocytosis of $\operatorname{PrP}^{\mathrm{C}}$. What is increasingly clear though is that expression of normal host $\operatorname{PrP}^{\mathrm{C}}$ is required for disease. Transgenic mice not expressing any $\operatorname{PrP}^{\mathrm{C}}$ cannot be infected with diseased tissue and neurons not expressing $\operatorname{PrP}^{\mathrm{C}}$ do not have $\operatorname{PrP}^{\mathrm{Sc}}$ induced toxicity. ${ }^{99}$

Mutant forms of $\operatorname{PrP}^{\mathrm{C}}$ that cause inherited prion disorders also have an altered conformation that makes them pathogenic and also sometimes infectious. About $10 \%-20 \%$ of human prion disease is inherited in an autosomal dominant fashion. A wide range of point mutations and insertions in Prnp on chromosome 20 has been identified that cause inheritable prion disorders. For example, the P102L mutation causes Gerstmann-Straussler-Scheinker syndrome, D178N causes either fatal familial insomnia or Creutzfeld-Jakob disease, and E200K causes a Creutzfeld-Jakob disease-like disease in Libyan Jews. In the $\mathrm{N}$-terminal half of $\operatorname{PrP}^{\mathrm{C}}$ there is a five repeat region (amino acids 51-91) composed of one nona-repeat and the four copper binding octa-repeats. Mutant $\operatorname{PrP}^{\mathrm{C}}$ variants carrying up to nine extra octa-repeats have been identified in patients presenting with various familial prion disorder phenotypes. Persons homozygous for a common methionine-valine polymorphism at codon 129 of $\operatorname{PrP}^{\mathrm{C}}$ are at increased risk for both sporadic (methionine) and iatrogenic (valine) Creutzfeld-Jakob disease. Interestingly, this polymorphism can also influence the phenotype of the D178N mutation; those with valine 129 on the mutant allele develop familial Creutzfeld-Jakob disease whereas methionine 129 is associated with fatal familiar insomnia. 
As with most of the proteins discussed in this review, it is not yet fully clear how, or even if, $\operatorname{PrP}^{\mathrm{sc}}$ and mutant $\operatorname{PrP}^{\mathrm{C}}$ actually cause neurodegeneration. A peptide corresponding to PrP106-126 can mimic $\operatorname{PrP}^{\mathrm{Sc}}$ neurotoxicity, an effect that requires the presence of host $\operatorname{PrP}^{\mathrm{C}}$ and also microglia, suggesting that oxidative stress may be involved. ${ }^{100}$ It could also be possible that $\operatorname{PrP}^{\mathrm{sc}}$ inhibits the normal cellular antioxidant function of $\operatorname{PrP}^{\mathrm{C}}$ and this further contributes to neurodegeneration. ${ }^{101}$ Understanding the normal biology of $\operatorname{PrP}^{\mathrm{C}}$, the mechanisms that convert it to the $\operatorname{PrP}^{\mathrm{sc}}$ isoform and how this and mutant $\operatorname{PrP}^{\mathrm{C}}$ isoforms are associated with cell death will no doubt illuminate the mysteries surrounding this most unusual protein and lead to the identification of novel therapies.

\section{HUNTINGTIN AND THE POLYGLUTAMINE TOXIC PROTEINS}

Huntington's disease (HD) was not expected to be a disorder associated with aggregation of proteins, toxic or otherwise. By contrast with the other neurodegenerative disorders we have been considering, inclusion bodies are not part of the characteristic pathology of the condition. It came as something of a surprise, therefore, to discover the hitherto hidden Huntington's disease inclusions and it took a transgenic mouse model to find them. In an effort to generate a model of Huntington's disease, mice were initially generated overexpressing the 5 '-end of the human Huntington's disease gene with CAG repeat expansions. ${ }^{102}$ Perhaps surprisingly, these mice developed a neurodegeneration strikingly similar to that of Huntington's disease and careful pathological studies revealed the accumulation of ubiquitinated huntingtin containing lesions in neuronal nuclei prior to neurodegeneration. ${ }^{103}$ Similar lesions, aggregates of both nuclear and neuropil ubiquitinated huntingtin protein fragments were then revealed in the brains of those with Huntington's disease. ${ }^{104-106}$ The normal huntingtin protein shows little tendency to self aggregate but in vitro, as well as in these animal models and in disease, huntingtin with amino terminal poylglutamine expansions readily self aggregates. ${ }^{107}$

The increased tendency of mutated huntingtin to aggregate is a direct result of the change in structural properties resulting from increased polyglutamine length in the protein. ${ }^{108}$ In cells in culture expression of the polyglutamine expansion also results in ubiquitinated intraneuronal and perineuronal lesions and increases the vulnerability of the cells to apoptosis, with a correlation between expansion size and toxicity. ${ }^{105}{ }^{109-111}$ Whether it is the nuclear or the cytoplasmic accumulation of huntingtin that results in neuronal toxicity is not entirely clear. Both occur in models and in disease ${ }^{112}$ and it may be that nuclear entry after proteolysis is a secondary step just as ubiquitination is likely to be. In line with this is a mouse transgenic expressing the human huntingtin gene using a yeast artificial chromosome which has demonstrable pathology before the appearance of nuclear aggregates. ${ }^{113}$

The finding that expression of only a minimal segment of the gene containing a poly-CAG repeat is sufficient to cause disease in animal models demonstrates, more clearly than for other neurodegenerative disorders, that it is a toxic gain of function rather than loss of the normal function of the resulting protein. The same is true for other polyglutamine triplet repeat disorders such as dentatorubro-pallidolusian atrophy. Questions remain in particular regarding the mechanism whereby the aggregations cause disease, possibly by interfering with neurotransmission ${ }^{14}$ and whether, for example, proteolysis is a necessary step. ${ }^{115}$

However, the really important step forward that results from the clear demonstration of toxic protein aggregates in Huntington's disease is towards therapy. Steps are being made to reduce aggregation of Huntington's disease protein, including the demonstration that formic acid dissolves aggregates, ${ }^{116}$ that antibodies directed against the molecule also reduce aggregation formation, ${ }^{117}$ that the heat shock protein chaperones might also reduce toxicity, ${ }^{118}{ }^{119}$ that inhibiting caspase cleavage reduces aggregation, ${ }^{108} 120121$ and that proteosome inhibition increases aggregation. ${ }^{122}$

\section{CONCLUSIONS}

Are there toxic proteins causing dementia? Not really. All the disorders we have considered, and others that we have not, are associated with inclusion bodies formed from proteins normally present and functioning in the brain. Whether it is the aggregation of these proteins that is toxic or whether it is loss of the normal function of these proteins that is toxic is not clear and some evidence suggests that the latter leads to the former in any case. There are some clear differences between the disorders - the amyloid aggregates of Alzheimer's disease are extracellular, the other aggregates are intracellular, some neuronal, some glial. For Alzheimer's disease other proteinsthe presenilins, APOE-have been identified through genetics that seem to alter the formation of the protein; no such proteins are known in the other disorders although the search is on.

Are there common aetiological mechanisms? It is possible, for example, that a decrease in protein degradation underlies these conditions. The proteosome might be a common final pathway to different dementias. Most recently it has been shown that protein aggregation inhibits the ubiquitinproteosome system leading to a positive feedback loop whereby this inhibition results in less protein degradation, more aggregation, more inhibition of the system and, presumably, in vivo, cell death. ${ }^{123}$

Despite some questions remaining to be answered, the identification of fibrillar aggregates in many neurodegenerative disorders raises the potential for therapy directed at preventing or clearing these aggregates. Different approaches are under consideration as illustrated by the search for disease modifying agents in Alzheimer's disease. One approach is to prevent or slow down the formation of the protein-for example, $\alpha$-secretase promotion, or BACE and $\gamma$-secretase inhibition, to prevent $A \beta$ formation. To prevent hyperphosphorylation of tau GSK-3 inhibitors might have some value-and one such, lithium-is in common use in another context. Such an approach makes complete sense but caution should be expressed as even $A \beta$ is likely to have a normal, if unknown, role in the adult brain. If it proves difficult to block prevention of the peptide then prevention of its aggregation by inhibition of conversion from native to $\beta$-sheet structure or blocking "nucleus" formation might be possible. Compounds to prevent aggregation are already approaching clinical trial phase in Alzheimer's disease. However, by far the most exciting development has been the demonstration that even when formed, there is considerable merit in clearing amyloid plaques. In a transgenic mutant APP overexpressing mouse, passive and active vaccination against $A \beta$ both cleared existing plaques and reversed cognitive decline. ${ }^{124}{ }^{125}$ The same approach is unlikely to be of use against intracellular inclusions but might be used against other extracellular aggregates- $\operatorname{PrP}^{\mathrm{sc}}$ for example. Finally efforts to reduce the effects of the toxicity of aggregates might find some common therapeutic goals across these disorders. From the finding that aggregation of proteins occurs in many different dementias, it is tempting to draw the conclusion that there are common pathological processes. There may be, but equally protein aggregation might be a common final pathway in neurodegeneration. However, the prospect that there might be common therapeutic strategies, if not common actual therapies, is an exciting one and one that should spur further research into toxic protein aggregation in dementia. 


\section{GLOSSARY OF TERMS}

Amyloid is generic term for abnormally aggregated proteins that usually have adopted a $\beta$-pleated sheet secondary structure.

Apoptosis is a form of programmed death for individual cells. It is characterised morphologically by plasma membrane blebbing and nuclear chromatin condensation and fragmentation. This all occurs in the absence of cell swelling or disintegration of other organelles and eventually serves to target the cell for phagocytosis by surrounding macrophages or microglia. The events leading to apoptosis are tightly regulated and involve a complicated cascade of enzymatic activities, including various members of the caspase family of enzymes.

Constitutive endoproteolysis is enzymatic cleavage within a protein that is continuously occurring, to a greater or lesser degree, independently of other cellular events.

Endocytosis is the process whereby the cell surface membrane progressively invaginates to eventually form a discrete membrane bound vesicle within the cytoplasm. Any membrane bound protein and the contents of this vesicle are thereby internalised from extracellular space into the cell body. Cell surface membrane bound APP can be reinternalised in this manner such that its ectodomain (or large extracellular domain) is no longer protruding into extracellular space but is now actually within a cellular vesicle.

A heterodimer is a complex comprised of two different proteins; a heterotrimeric complex contains three different proteins; a homodimeric complex contains two of the same protein, etc.

Notch is a single membrane spanning cell surface protein that acts in cell signalling and has a central role in neurodevelopment. Similar to APP, it undergoes endoproteolysis within its transmembrane domain. This seems to be due to the same $\gamma$-secretase that cleaves APP to generate A $\beta$ and is also dependent upon the presenilin proteins.

Phosphorylation is the biochemical process in which a phosphate group is attached to another molecule. For proteins this is achieved by kinase enzymes. Phosphorylation of proteins is a key method of regulating their activity.

Protein structure can be described in four different levels of complexity. Primary structure is simply the linear sequence of amino acids. Secondary structure is essentially the $\alpha$-helical and $\beta$-strand arrangements formed by short sequences of continuous amino acids. Tertiary structure is how these $\alpha$-helices and $\beta$-strands, plus intervening less well structurally defined sequences, are positioned relative to each other in 3 dimensional space. Quaternary structure is how larger well defined protein subunits relate to each other in three dimensional space. To some extent the secondary structure of a protein can be deduced from the primary structure. However, tertiary and quaternary structures are not readily predictable and solving structure at this level requires complicated analysis.

Ubiquitin is a small conserved intracellular protein that binds other proteins, targeting them for degradation. Once a protein is ubiquitinated it is directed towards the proteosome, which is a multiprotein complex containing a range of protease enzymes. The proteases break down peptide bonds between amino acids in the ubiquitinated protein. After degradation of the protein, ubiquitin molecules are released and recycled

\section{ACKNOWLEDGEMENTS}

Work in our laboratories is supported by the Wellcome Trust, the MRC, The EU, the Alzheimer's Society and The Alzheimer's Research Trust.

\section{Authors' affiliations}

S Lovestone, D M McLoughlin, Section of Old Age Psychiatry, Institute of Psychiatry, De Crespigny Park, London SE5 8AF, UK

\section{REFERENCES}

1 Selkoe DJ. Translating cell biology into therapeutic advances in Alzheimer's disease. Nature 1999;399(suppl):A23-31.

2 Iwatsubo T, Odaka A, Suzuki N, et al. Visualization of A $342(43)$ and $A \beta 40$ in senile plaques with end-specific $A \beta$ monoclonals: evidence that an initially deposited species is A $342(43)$. Neuron 1994;13:45-53.

3 Teller JK, Russo C, DeBusk LM, et al. Presence of soluble amyloid $\beta$-peptide precedes amyloid plaque formation in Down's syndrome. Nat Med 1996;2:93-5

4 Vickers JC, Dickson TC, Adlard PA, et al. The cause of neuronal degeneration in Alzheimer's disease. Prog Neurobiol 2000;60: 139-65

5 Price DL, Sisodia SS. Mutant genes in familial Alzheimer's disease and transgenic models. Annu Rev Neurosci 1998;21:479-505.

6 Cummings BJ, Cotman CW. Image analysis of $\beta$-amyloid load in Alzheimer's disease and relation to dementia severity. Lancet 1995;346:1524-8

7 Braak H, Braak E. Neuropathological stageing of Alzheimer-related changes. Acta Neuropathol (Berl) 1991;82:239-59.

8 Janus C Chishti MA, Westaway D. Transgenic mouse models of Alzheimer's disease. Biochimica et Biophysica Acta: Molecular Basis Of Disease 2000;1502:63-75

9 Selkoe DJ. The cell biology of $\beta$-amyloid precursor protein and presenilin in Alzheimer's disease. Trends Cell Biol 1998;8:447-53.

10 Vassar R, Bennett BD, Babu-Khan S, et al. $\beta$-Secretase cleavage of Alzheimer's amyloid precursor protein by the transmembrane aspartic protease BACE. Science 1999;286:735-41.

11 Hussain I, Powell DJ, Howlett DR, et al. Identification of a novel aspartic protease (Asp 2) as $\beta$-secretase. Mol Cell Neurosci 1999;14:419-27.

12 Yan RQ, Bienkowski M, Shuck ME, et al. Membrane-anchored aspartyl protease with Alzheimer's disease $\beta$ - secretase activity. Nature 1999;402:533-7.

13 Sinha S, Anderson JP, Barbour R, et al. Purification and cloning of amyloid precursor protein $\beta$ - secretase from human brain. Nature 1999:402:537-40

14 Lin XL, Koelsch C, Wu SL, et al. Human aspartic protease memapsin 2 cleaves the $\beta$-secretase site of $\beta$-amyloid precursor protein. Proc Natl Acad Sci USA 2000; 97: 1456-60

15 Saunders AJ, Kim T-W, Tanzi RE. BACE maps to chromosome 11 and a $B A C E$ homolog, $B A C E 2$, reside in the obligate Down syndrome region of chromosome 21. Science 1999:286:1255a

16 Bennett BD, Babu-Khan S, Loeloff R, et al. Expression analysis of BACE2 in brain and peripheral tissues. J Biol Chem 2000;275:20647-51.

17 Farzan $M$, Schnitzler CE, Vasilieva $N$, et al. BACE2, a $\beta$-secretase homolog, cleaves at the $\beta$-site and within the amyloid- $\beta$ region of the amyloid- $\beta$ precursor protein. Proc Natl Acad Sci USA 2000;97:9712-7.

18 Annaert W, De Strooper B. Presenilins: molecular switches between proteolysis and signal transduction. Trends Neurosci 1999;22:439-43.

19 Wong PC, Zheng H, Chen $\mathrm{H}$, et al. Presenilin 1 is required for Notch 1 DIll expression in the paraxial mesoderm. Nature 1997;387:288-92.

20 Shen J, Bronson RT, Chen DF, et al. Skeletal and CNS defects in presenilin-1-deficient mice. Cell 1997;89:629-39.

21 Conlon RA, Reaume AG, Rossant J. Notch 1 is required for the coordinate segmentation of somites. Development 1995;121:1533-45.

22 De Strooper B, Saftig P, Craessaerts K, et al. Deficiency of presenilin-1 inhibits the normal cleavage of amyloid precursor protein. Nature 1998:391:387-90.

23 Naruse S, Thinakaran G, Luo JJ, et al. Effects of PS 1 deficiency on membrane protein trafficking in neurons. Neuron 1998;21:1213-21.

24 Zhang ZH, Nadeau P, Song WH, et al. Presenilins are required for $\gamma$-secretase cleavage of $\beta$-APP and transmembrane cleavage of Notch- 1 . Nat Cell Biol 2000;2:463-5.

25 Wolfe MS, Xia W, Ostaszewski BL, et al. Two transmembrane aspartates in presenilin-1 required for presenilin endoproteolysis and gamma-secretase activity. Nature 1999;398:513-7.

26 Capell A, Steiner H, Romig H, et al. Presenilin-1 differentially facilitates endoproteolysis of the $\beta$-amyloid precursor protein and notch. Nat Cell Biol 2000;2:205-1 1

27 Esler WP, Kimberly WT, Ostaszewski BL, et al. Transition-state analogue inhibitors of $\gamma$-secretase bind directly to presenilin-1. Nat Cell Biol 2000;2:428-34

28 Li YM, Xu M, Lai MT, et al. Photoactivated $\gamma$-secretase inhibitors directed to the active site covalently label presenilin 1. Nature 2000;405:68994

29 Li YM, Lai MT, Xu M, et al. Presenilin 1 is linked with $\gamma$-secretase activity in the detergent solubilized state. Proc Natl Acad Sci USA 2000:97:6138-43.

30 Meyer MR, Tschanz JT, Norton MC, et al. ApoE genotype predicts when, not whether, one is predisposed to develop Alzheimer disease. Nat Genet 1998;19:321-2.

31 Bales KR, Verina T, Dodel RC, et al. Lack of apolipoprotein E dramatically reduces amyloid $\beta$ - peptide deposition. Nat Genet 1997; 17:263-4.

32 Schmechel DE, Saunders AM, Strittmatter WJ, et al. Increased amyloid $\beta$-peptide deposition in cerebral cortex as a consequence of apolipoprotein E genotype in late-onset Alzheimer disease. Proc Natl Acad Sci USA 1993:90:9649-53.

33 Strittmatter WJ, Weisgraber KH, Huang DY, et al. Binding of human apolipoprotein $\mathrm{E}$ to synthetic amyloid $\beta$ peptide: isoform-specific effects and implications for late-onset Alzheimer disease. Proc Natl Acad Sci USA 1993:90:8098-102.

34 Strittmatter WJ, Weisgraber KH, Goedert M, et al. Microtubule instability and paired helical filament formation in the Alzheimer disease 
brain are related to apolipoprotein E genotype. Exp Neurol 1994; 125:163-71.

35 Strittmatter WJ, Saunders AM, Goedert M, et al. Isoform-specific interactions of apolipoprotein $\mathrm{E}$ with microtubule-associated protein tau: implications for Alzheimer disease. Proc Natl Acad Sci USA 1994:91:11183-6.

36 Beffert U, Danik M, Krzywkowski P, et al. The neurobiology of apolipoproteins and their receptors in the CNS and Alzheimer's disease. Brain Res Rev 1998;27: 119-42.

37 Hiesberger T, Trommsdorff $M$, Howell BW, et al. Direct binding of reelin to $\mathrm{VLDL}$ receptor and apoE receptor 2 induces tyrosine phosphorylation of disabled-1 and modulates tau phosphorylation. Neuron 1999;24:481-9.

38 Trommsdorff M, Borg JP, Margolis B, et al. Interaction of cytosolic adaptor proteins with neuronal apolipoprotein $\mathrm{E}$ receptors and the amyloid precursor protein. J Biol Chem 1998;273:33556-60.

39 Russo T, Faraonio R, Minopoli G, et al. Fe65 and the protein network centered around the cytosolic domain of the Alzheimer's $\beta$-amyloid precursor protein. FEBS Lett 1998;434:1-7.

40 Sabo SL, Lanier LM, Ikin AF, et al. Regulation of $\beta$-amyloid secretion by FE65, an amyloid protein precursor-binding protein. J Biol Chem 1999:274:7952-7.

41 Guenette SY, Chen J, Ferland A, et al. hFE65L influences amyloid precursor protein maturation and secretion. J Neurochem 1999;73:985-93.

42 Borg JP, Yang Y, Taddeo-Borg $M$, et al. The X $11 \alpha$ protein slows cellula amyloid precursor protein processing and reduces $A \beta 40$ and $A \beta 42$ secretion. J Biol Chem 1998;273:14761-6.

43 Sastre $M$, Turner RS, Levy E. X 11 interaction with $\beta$-amyloid precursor protein modulates its cellular stabilization and reduces amyloid $\beta$-protein secretion. J Biol Chem 1998;273:22351-7.

44 McLoughlin DM, Irving NG, Miller CCJ. The Fe65 and XII families of proteins: proteins that interact with the Alzheimer's disease amyloid precursor protein. Biochem Soc Trans 1998;26:497-500.

45 Tomita S, Ozaki T, Taru H, et al. Interaction of a neuron-specific protein containing PDZ domains with Alzheimer's amyloid precursor protein. $J$ Biol Chem 1999·274:2243-54

46 Lau KF, Mcloughlin DM, Standen $C$, et al. X $11 \alpha$ and $X 11 \beta$ interact with presenilin-1 via their PDZ domains. Mol Cell Neurosci 2000; 16:557-65.

47 Ulery PG, Beers J, Mikhailenko I, et al. Modulation of $\beta$-amyloid precursor protein processing by the low density lipoprotein receptor-related protein (LRP): evidence that LRP contributes to the pathogenesis of Alzheimer's disease. J Biol Chem 2000;275:7410-5

48 Kehoe P, Wavrant-De Vrieze F, Crook R, et al. A full genome scan for late onset Alzheimer's disease. Hum Mol Genet 1999:8:237-45.

49 Blacker D, Wilcox MA, Laird NM, et al. Alpha-2 macroglobulin is genetically associated with Alzheimer disease. Nat Genet 1998;19:357-60.

50 Ertekin-Taner N, Graff-Radford N, Younkin LH, et al. Linkage of plasma $\mathrm{A} \beta 42$ to a quantitative locus on chromosome 10 in late-onset Alzheimer's disease pedigrees. Science 2000:290:2303-4.

51 Myers A, Holmans P, Marshall H, et al. Susceptibility locus for Alzheimer's disease on chromosome 10. Science 2000;290:2304-5.

52 Bertram L, Blacker D, Mullin K, et al. Evidence for genetic linkage of Alzheimer's disease to chromosome 10q. Science 2000;290:2302-3

53 Vekrellis K, Ye Z, Qiu WQ, et al. Neurons regulate extracellular levels of amyloid $\beta$-protein via proteolysis by insulin-degrading enzyme. J Neurosci 2000;20: 1657-65.

54 Grundke Iqbal I, lqbal K, Tung YC, et al. Abnormal phosphorylation of the microtubule-associated protein tau (tau) in Alzheimer cytoskeletal pathology. Proc Natl Acad Sci USA 1986;83:4913-7.

55 Kosik KS, Joachim CL, Selkoe DJ. Microtubule-associated protein tau (tau) is a major antigenic component of paired helical filaments in Alzheimer disease. Proc Natl Acad Sci USA 1986;83:4044-8.

56 Spillantini MG, Goedert M. Tau protein pathology in neurodegenerative diseases. Trends Neurosci 1998;21:428-33.

57 Lee VMY. Regulation of tau phosphorylation in Alzheimer's disease. Ann NY Acad Sci 1996;777:107-13.

58 Lovestone S, Reynolds $\mathrm{CH}$. The phosphorylation of tau: a critical stage in neurodevelopmental and neurodegenerative processes. Neuroscience 1997;78:309-24.

59 Buée L, Bussière T, Buée-Scherrer $V$, et al. Tau protein isoforms, phosphorylation and role in neurodegenerative disorders. Brain Res Rev 2000;33:95-130.

60 Heutink P. Untangling tau-related dementia. Hum Mol Genet 2000;9:979-86.

61 Buee L, Delacourte A. Comparative biochemistry of tau in progressive supranuclear palsy, corticobasal degeneration, FTDP-17 and Pick's disease. Brain Pathol 1999;9:681-93.

62 Murrell JR, Spillantini MG, Zolo $P$, et al. Tau gene mutation G389R causes a tauopathy with abundant pick body-like inclusions and axonal deposits. J Neuropathol Exp Neurol 1999;58:1207-26.

63 Rizzini C, Goedert M, Hodges JR, et al. Tau gene mutation K257T causes a tauopathy similar to Pick's disease. J Neuropathol Exp Neurol 2000:59:990-1001.

64 Baker M, Litvan I, Houlden $\mathrm{H}$, et al. Association of an extended haplotype in the tau gene with progressive supranuclear palsy. Hum Mol Genet 1999;8:711-5.

65 Grover A, Houlden H, Baker M, et al. 5' Splice site mutations in tau associated with the inherited dementia FTDP-17 affect a stem-loop structure that regulates alternative splicing of exon 10. J Biol Chem 1999;274: 15134-43.
66 Hasegawa M, Smith M, Goedert M. Tau proteins with FTDP-17 mutations have a reduced ability to promote microtubule assembly. FEBS Lett. 1998;437:207-10

67 Hong M, Zhukareva V, Vogelsberg-Ragaglia V, et al. Mutation-specific functional impairments in distinct tau isoforms of hereditary FTDP-17. Science 1998;282:1914-7.

68 Dayanandan R, Van Slegtenhorst M, Mack TG, et al. Mutations in tau reduce its microtubule binding properties in intact cells and affect its phosphorylation. FEBS Lett 1999:446:228-32.

69 Arrasate M, Perez M, Armas-Portela R, et al. Polymerization of tau peptides into fibrillar structures. The effect of FTDP-17 mutations. FEBS Lett 1999;446: 199-202.

70 Nacharaju P, Lewis J, Easson C, et al. Accelerated filament formation from tau protein with specific FTDP-17 missense mutations. FEBS Lett 1999:447: 195-9.

71 Lewis J, McGowan E, Rockwood J, et al. Neurofibrillary tangles, amyotrophy and progressive motor disturbance in mice expressing mutant (P301L) tau protein. Nat Genet 2000;25:402-5.

72 Mann DM, Esiri MM. The pattern of acquisition of plaques and tangles in the brains of patients under 50 years of age with Down's syndrome. $J$ Neurol Sci 1989;89: 169-79.

73 Braak H, Braak E. Staging of Alzheimer's disease-related neurofibrillary changes. Neurobiol Aging 1995:16:271-8.

74 Lovestone S, Hartley CL, Pearce J, et al. Phosphorylation of tau by glycogen synthase kinase- $3 \beta$ in intact mammalian cells: the effects on organisation and stability of microtubules. Neuroscience 1996:73:1145-57.

75 Mena R, Edwards PC, Harrington CR, et al. Staging the pathological assembly of truncated tau protein into paired helical filaments in Alzheimer's disease. Acta Neuropathol (Berl) 1996;91:633-41

76 Bondareff W, Harrington CR, Wischik CM, et al. Absence of abnormal hyperphosphorylation of tau in intracellular tangles in Alzheimer's disease. J Neuropathol Exp Neurol 1995;54:657-63.

77 Hasegawa $M$, Crowther RA, Jakes B, et al. Alzheimer-like changes in microtubule-associated protein tau induced by sulfated glycosaminoglycans - Inhibition of microtubule binding, stimulation of phosphorylation, and filament assembly depend on the degree of sulfation. J Biol Chem 1997;272:33118-24.

78 Brookes AJ, St Clair D. Synuclein proteins and Alzheimer's disease. Trends Neurosci 1994:17:404-5.

79 Jin H, Clayton DF. Synelfin regulation during the critical period for song learning in normal and isolated juvenile zebra finches. Neurobiol Learn Mem 1997; 68:271-84

80 Spillantini MG, Schmidt ML, Lee VM, et al. Alpha-synuclein in Lewy bodies. Nature 1997:388:839-40.

81 Wakabayashi K, Matsumoto K, Takayama K, et al. NACP, a presynaptic protein, immunoreactivity in Lewy bodies in Parkinson's disease. Neurosci Lett 1997;239:45-8.

82 Baba M, Nakajo S, Tu PH, et al. Aggregation of $\alpha$-synuclein in Lewy bodies of sporadic Parkinson's disease and dementia with lewy bodies. Am J Pathol 1998;152:879-84.

83 Polymeropoulos $\mathbf{M H}$, Lavedan C, Leroy $\mathrm{E}$, et al. Mutation in the $\alpha$-synuclein gene identified in families with Parkinson's disease. Science 1997; 276:2045-7.

84 Dickson DW, Lin WL, Liu WK, et al. Multiple system atrophy: a sporadic synucleinopathy. Brain Pathol 1999;9:721-32.

85 Feany MB, Bender WW. A drosophila model of Parkinson's disease. Nature 2000:404:394-8.

86 Masliah E, Rockenstein E, Veinbergs I, et al. Dopaminergic loss and inclusion body formation in alpha-synuclein mice: implications for neurodegenerative disorders. Science 2000;287: 1265-9.

87 Withers GS, George JM, Banker GA, et al. Delayed localization of synelfin (synuclein, NACP) to presynaptic terminals in cultured rat hippocampal neurons. Dev Brain Res 1997;99:87-94.

88 Hsu LJ, Mallory M, Xia Y, et al. Expression pattern of synucleins (non-A $\beta$ component of Alzheimer's disease amyloid precursor protein $\alpha$-synuclein) during murine brain development. J Neurochem 1998;71:338-44.

89 Abeliovich A, Schmitz Y, Farinas I, et al. Mice lacking alpha-synuclein display functional deficits in the nigrostriatal dopamine system. Neuron 2000;25:239-52.

90 Conway KA, Harper JD, Lansbury PT. Accelerated in vitro fibril formation by a mutant $\alpha$-synuclein linked to early-onset Parkinson disease. Nat Med 1998;4:1318-20.

91 El Agnaf OM, Jakes R, Curran MD, et al. Effects of the mutations Ala30 to Pro and Ala53 to Thr on the physical and morphological properties of $\alpha$-synuclein protein implicated in Parkinson's disease. FEBS Lett 1998:440:67-70

92 Narhi L, Wood SJ, Steavenson S, et al. Both familial Parkinson's disease mutations accelerate $\alpha$-synuclein aggregation. J Biol Chem 1999:274:9843-6.

93 Wood SJ, Wypych J, Steavenson S, et al. a-Synuclein fibrillogenesis is nucleation-dependent: implications for the pathogenesis of Parkinson's disease. J Biol Chem 1999;274:19509-12.

94 Bennett MC, Bishop JF, Leng Y, et al. Degradation of $\alpha$-synuclein by proteasome. J Biol Chem 1999;274:33855-8.

95 Harris DA. Cellular biology of prion diseases. Clin Microbiol Revs 1999; 12:429-44.

96 Bruce ME, Will RG, Ironside JW, et al. Transmissions to mice indicate that "new variant" CJD is caused by the BSE agent. Nature 1997;389:498-501. 
97 Brown DR, Qin KF, Herms JW, et al. The cellular prion protein binds copper in vivo. Nature 1997;390:684-7.

98 Whittington MA, Sidle KCL, Gowland I, et al. Rescue of neurophysiological phenotype seen in PrP null mice by transgene encoding human prion protein. Nat Genet 1995;9:197-201.

99 Telling GC. Prion protein genes and prion diseases: studies in transgenic mice. Neuropathol App/ Neurobiol 2000;26:209-20.

100 Brown DR, Schmidt B, Kretzschmar HA. Role of microglia and host prion protein in neurotoxicity of a prion protein fragment. Nature 1996;380:345-7.

101 Brown DR. PrPSc-like prion protein peptide inhibits the function of cellular prion protein. Biochem J 2000;352:51 1-8.

102 Mangiarini L, Sathasivam K, Seller M, et al. Exon 1 of the HD gene with an expanded CAG repeat is sufficient to cause a progressive neurological phenotype in transgenic mice. Cell 1996;87:493-506.

103 Davies SW, Turmaine M, Cozens BA, et al. Formation of neuronal intranuclear inclusions underlies the neurological dysfunction in mice transgenic for the HD mutation. Cell 1997;90:537-48.

104 Difiglia M, Sapp E, Chase KO, et al. Aggregation of huntingtin in neuronal intranuclear inclusions and dystrophic neurites in brain. Science 1997;277:1990-3

105 Martindale D, Hackam A, Wieczorek A, et al. Length of huntingtin and its polyglutamine tract influences localization and frequency of intracellular aggregates. Nat Genet 1998;18:150-4.

106 Gutekunst CA, Li SH, Yi H, et al. Nuclear and neuropil aggregates in Huntington's disease: relationship to neuropathology. J Neurosci 1999; 19:2522-34.

107 Scherzinger E, Lurz R, Turmaine $M$, et al. Huntingtin-encoded polyglutamine expansions form amyloid-like protein aggregates in vitro and in vivo. Cell 1997;90:549-58.

108 Perutz MF. Glutamine repeats and neurodegenerative diseases: molecular aspects. Trends Biochem Sci 1999;24:58-63.

109 Cooper JK, Schilling G, Peters MF, et al. Truncated N-terminal fragments of huntingtin with expanded glutamine repeats form nuclear and cytoplasmic aggregates in cell culture. Hum Mol Genet 1998;7:783-90.

110 Hackam AS, Singaraja R, Wellington CL, et al. The influence of huntingtin protein size on nuclear localization and cellular toxicity. J Cell Biol 1998;141:1097-105.

111 Lunkes A, Mandel JL. A cellular model that recapitulates major pathogenic steps of Huntington's disease. Hum Mol Genet 1998; 7:1355-61.

112 Hackam AS, Singaraja R, Zhang T, et al. In vitro evidence for both the nucleus and cytoplasm as subcellular sites of pathogenesis in Huntington's disease. Hum Mol Genet 1999;8:25-33.
113 Hodgson JG, Agopyan N, Gutekunst CA, et al. A YAC mouse model for Huntington's disease with full-length mutant huntingtin, cytoplasmic toxicity, and selective striatal neurodegeneration. Neuron 1999;23:181-92.

$114 \mathrm{Li} \mathrm{H}$, Li SH, Cheng AL, et al. Ultrastructural localization and progressive formation of neuropil aggregates in Huntington's disease transgenic mice. Hum Mol Genet 1999;8:1227-36.

115 Ellerby LM, Andrusiak RL, Wellington CL, et al. Cleavage of atrophin-1 at caspase site aspartic acid 109 modulates cytotoxicity. J Biol Chem 1999;274:8730-6.

116 Hazeki N, Tukamoto T, Goto J, et al. Formic acid dissolves aggregates of an $\mathrm{N}$-terminal huntingtin fragment containing an expanded polyglutamine tract: applying to quantification of protein components of the aggregates. Biochem Biophys Res Commun 2000;277:386-93.

117 Heiser V, Scherzinger E, Boeddrich A, et al. Inhibition of huntingtin fibrillogenesis by specific antibodies and small molecules: implications for Huntington's disease therapy. Proc Natl Acad Sci USA 2000;97:6739-44.

118 Jana NR, Tanaka M, Wang G, et al. Polyglutamine length-dependent interaction of $\mathrm{Hsp} 4 \mathrm{O}$ and $\mathrm{Hsp} 70$ family chaperones with truncated $\mathrm{N}$-terminal huntingtin: their role in suppression of aggregation and cellular toxicity. Hum Mol Genet 2000;9:2009-18.

119 Muchowski PJ, Schaffar G, Sittler A, et al. Hsp70 and hsp40 chaperones can inhibit self-assembly of polyglutamine proteins into amyloid-like fibrils. Proc Natl Acad Sci USA 2000;97:7841-6.

120 Diamond MI, Robinson MR, Yamamoto KR. Regulation of expanded polyglutamine protein aggregation and nuclear localization by the glucocorticoid receptor. Proc Natl Acad Sci USA 2000;97:657-61.

121 Wellington CL, Singaraja R, Ellerby L, et al. Inhibiting caspase cleavage of huntingtin reduces toxicity and aggregate formation in neuronal and non-neuronal cells. J Biol Chem 2000;275:19831-8.

122 Wyttenbach A, Carmichael J, Swartz J, et al. Effects of heat shock, heat shock protein 40 (HDJ-2), and proteasome inhibition on protein aggregation in cellular models of Huntington's disease. Proc Natl Acad Sci USA 2000;97:2898-903.

123 Bence CF, Sampat RM, Kopito RR. Impairment of the ubiquitin-proteosome system by protein aggrgegtaion. Science 2001;292:1552-5.

124 Schenk D, Barbour R, Dunn W, et al. Immunization with amyloid- $\beta$ attenuates Alzheimer disease like pathology in the PDAPP mouse. Nature 1999;400:173-7.

125 Janus C, Pearson J, Mclaurin J, et al. A $\beta$ peptide immunization reduces behavioural impairment and plaques in a model of Alzheimer's disease. Nature 2000;408:979-82. 